\title{
HACIA UNA ARQUEOLOGÍA DE LA ADMINISTRACIÓN*
}

\author{
Juan Carlos Jurado Jurado
}

doi: 10.11144/Javeriana.cao28-50.haam. Este artículo es producto de la investigación “Conformación histórica de la Administración. Una mirada desde la escritura" financiado por la Universidad EAFIT desde enero de 2013 hasta diciembre de 2013. El artículo se recibió el 16/09/2014 y se aprobó el 30/05/2015. Sugerencia de citación: Jurado J., J. C. (2015). Hacia una arqueología de la administración. Cuadernos de Administración, 50 (28), 113-136. http://dx.doi.org/10.11144/Javeriana.cao28-50.haam

** Doctor en Historia de la Universidad de Huelva, España, 2010. Profesor del Departamento de Organización y Gerencia de la Universidad EAFIT de Medellín, Colombia.

Correo electrónico:jjurado@eafit.edu.co 


\section{Hacia una arqueología de la administración}

\section{RESUMEN}

La administración nació con las obras escritas de Taylor (1911) y Fayol (1916), sin embargo, ello es resultado de procesos acecidos durante la Revolución Industrial (1780-1900) (momento arqueológico). Como objeto de este artículo se analiza el papel que tuvieron, durante ese período, los escritos de los empresarios acerca de sus prácticas de organización del trabajo en las industrias, en la formación de la administración. Se hace una revisión hermenéutico-crítica de bibliografía primaria y secundaria y se halla que antes de tales obras existió una tradición de los empresarios por expresar textualmente sus conocimientos empíricos (prácticas administrativas), de allí que la escritura fuera fundamental en la conformación de la administración como una práctica productora de su propio saber teórico (práctica discursiva).

Palabras clave: administración, prácticas administrativas, práctica discursiva, escritura en administración.

Clasificación JEL: M11

\section{Towards an Archaeology of Management}

\section{ABSTRACT}

Management came into being thanks to the written works of both Taylor (1911) and Fayol (1916); nevertheless, it is the result of processes that took place during the Industrial Revolution (1780-1900) (archaeological moment). This paper addresses the role that the entrepreneurs' writings on their work organization practices in industries played in the formation of management during that period. After a critical-hermeneutic review of primary and secondary bibliography, it was found that, before the existence of such works, entrepreneurs had a tradition of expressing their empirical knowledge (management practices) in texts, thereby indicating that writing was fundamental in shaping management as a practice that produces its own theoretical knowledge (discursive practice).

Keywords: management, management practices, discursive practice, writing in management.

JEL Classification: M11

\section{Rumo a uma arqueologia da Administração}

\section{RESUMO}

A administração nasceu com as obras de Taylor (1911) e Fayol (1916); contudo, isso é resultado de processos ocorridos durante a Revolução Industrial (1780-1900 momento arqueológico). O objetivo deste artigo é analisar o papel que os textos dos empresários sobre suas práticas de organização do trabalho nas indústrias tiveram na formação da administração durante esse período. Faz-se uma revisão hermenêutico-crítica de bibliografia primária e secundária e constata-se que, antes de tais obras, existiu uma tradição dos empresários por expressarem textualmente seus conhecimentos empíricos (práticas administrativas), o que demonstra que a escrita era fundamental na conformação da administração como uma prática produtora de seu próprio saber teórico (prática discursiva).

Palavras-chave: administração, práticas administrativas, prática discursiva, escrita em administração.

Classificação JEL: M11 


\section{Introducción: la Administración como práctica económica y cultural pre-moderna}

La antropología ha mostrado que en las sociedades pre-modernas no existía la tajante separación que hoy se presenta entre los ámbitos de la vida política, económica y cultural. En tales sociedades la vida social era un continuum de diversas dimensiones de lo humano, de manera que la construcción cotidiana de realidad se significaba desde las mismas prácticas sociales amalgamadas en un todo orgánico. Lo que hoy entendemos como "administración", un "saber experto" y una función profesional que se despliega exclusivamente en escenarios productivos como las organizaciones, no estaba separado de otras esferas de la vida social ${ }^{1}$. Lo que hoy conocemos como administración era realmente una "práctica" sin discurso y sin una doctrina propia, lo que en las sociedades modernas significa fundamentalmente un corpus teórico llamado ciencia.

La "práctica" puede ser entendida como todo acto rutinario establecido culturalmente por un grupo humano en diversos órdenes de la organización social, definida por un quehacer, una especie de praxis. Toda práctica implica unas regularidades traducibles a la "acción social" (Abbagnano, 2001, pp. 939-942). Para Michel De Certeau, las prácticas constituyen las "maneras de hacer" de los grupos sociales, "modos de operación" 0 "esquemas de acción" que se remontan a los ardides milenarios de las especies animales en su relación con el medio y que quedan ocultas tras la racionalidad dominante en 0ccidente. Se trata de los usos y "artes de hacer" que definen las formas de apropiación y recepción de los productos y dispositivos que el orden dominante impone a los diversos grupos de la sociedad (De Certeau, 2007, pp. XLI-LV). Para el historiador francés Roger Chartier "la noción de práctica es inseparable de la de representación, en la medida en que designa las conductas ritualizadas o espontáneas que, acompañadas o no de discurso, manifiestan (o revelan) las identidades y hacen reconocer el poder". Las prácticas se refieren a “conductas automáticas y espontáneas" (2000, pp. 124-125).

Dado que el hombre ha debido interactuar con el mundo natural para aprovechar los recursos que garanticen su bienestar, históricamente ha sido necesaria una serie de actividades que podrían denominarse "prácticas administrativas", y que están en el orden de la disposición, manejo, organización y control eficiente de recursos de diverso orden. Aunque las prácticas administrativas podían valerse de dispositivos escritos en las socie-

1 El "saber experto" se refiere a "un sistema abstracto de comprensión del mundo que contribuye -positiva o negativamente- a la formación y representación de la vida social" (Díaz, 2010, p. 14). 
dades pre-modernas, su naturaleza comunicativa era esencialmente oral (Podestá y Jurado, 2003). Para Hernández y Rodríguez (1994) las prácticas administrativas constituyen un saber altamente empírico y efectivo para lograr los objetivos de bienestar colectivo, construido culturalmente mediante ensayo y error. Este complejo de conocimientos empíricos tenía lugar en las condiciones materiales de la existencia, con la capacidad del hombre para insertarse en las relaciones de producción y de trabajo y transformarlas activamente. Durante siglos, estas prácticas estuvieron insertas en las rutinarias acciones económicas y culturales que posteriormente se identificaron en el Occidente moderno con un campo de discursos autónomo, ligado exclusivamente a la producción racional de bienes y servicios, lo que constituyó un saber específico y especializado con pretensiones de cientificidad (Nagel, 1994; González, 2005).

La centralidad de las prácticas administrativas en la organización de grandes conglomerados humanos exigía "un alto grado de organización económica, administrativa y militar". Ello se aprecia desde las "altas culturas" (Egipto, Acadia, Babilonia, Asiria, Hitita), entre los milenios IV y III antes de nuestra era, hasta la Edad Media, con la existencia de un intrincado orden administrativo, como resultado de la estrecha y jerarquizada organización que alcanzaron estas sociedades, con un férreo dominio territorial para sus asentamientos poblacionales. Según Manuel García-Pelayo, en este contexto tuvo lugar la aparición de un "orden político" que requirió de todo un "orden administrativo", con miras a la sostenibilidad de las mencionadas civilizaciones. La existencia de éstas supuso la institucionalización de mecanismos de poder y dominación, la definición jerarquizada de fines colectivos, la elección de los medios para conseguirlos, la división horizontal y vertical del trabajo, la extracción y distribución de excedentes de una parte de la producción para destinarla a obras como templos, palacios, canales, fortalezas, obras públicas y vías de comunicación que benefician a la colectividad, pero sobre todo, a sus estratos dominantes (García-Pelayo, 1981; Charbonnier, 2006).

En correspondencia con lo anterior, el antropólogo Claude Lévi-Struss ha planteado que la aparición de la escritura no se explica sin la organización de sistemas de dominación y explotación de unos hombres por otros, propio de las sociedades de castas o de clases, al decir que: "Cuando nos preguntamos a qué gran fenómeno social estaba ligada la aparición de la escritura, siempre y en todas partes, estuvimos de acuerdo, creo, en que la única realidad sociológica concomitante con la escritura era la aparición de fisiones, de escisiones, correspondientes a regímenes de castas o de clase, pues la escritura se nos presentó en sus comienzos como un medio para que unos hombres sometieran a otros, para gobernar a los hombres y apropiarse de las cosas" (Charbonnier, 2006, p. 71). 
Al indagar por la organización de algunas sociedades del Cercano Oriente Antiguo (Egipto y Mesopotamia), el antropólogo Jack Goody ha mostrado la profunda interdependencia entre sistemas sociales jerarquizados, sistemas administrativos y la escritura. Esta última sirvió, al modo de una técnica estratégica para el funcionamiento de los complejos sistemas sociales estratificados, que requirieron importantes niveles de alfabetismo a quienes cumplían una intrincada red de funciones gubernamentales, religiosas y administrativas. En las sociedades mencionadas, la formalización de dispendiosos procedimientos administrativos promovió la escritura y, al mismo tiempo, ésta fue soporte para aquellos: una rica trama de prácticas administrativas que fue necesaria para el funcionamiento de una estructura burocrática, tanto civil como religiosa, en los asuntos agrícola, pecuario, minero, artesanal, contable, tributario, comercial y en los "del templo y el palacio" (Goody, 1990, p. 69). Parafraseando a Goody (1990) y Walter Ong (2009) la escritura fue fundamental en la ampliación de las posibilidades de la administración y de la economía de estas sociedades.

No obstante la interdependencia entre escritura y prácticas administrativas, los registros arqueológicos indican que se escribía fundamentalmente "para" garantizar la efectividad en el manejo de grandes cantidades de recursos y de hombres. De igual modo la escritura permitió ampliar la capacidad del manejo contable de ingentes cantidades de bienes y servicios en sociedades donde la memoria oral era importante, pero que se veía rebasada por la magnitud y complejidad del sistema social y económico (Gellner, 2003). En suma, la escritura fue un medio y una técnica más, entre otras, "para" garantizar eficiencia y eficacia en los procesos económicos y administrativos de todo orden. Se trataba de toda una técnica de poder administrativo. Como se expondrá más adelante, esto constituye una diferencia crucial con las sociedades modernas de 0ccidente, en las cuales se logra trascender la escritura como un medio y una técnica "para" administrar, y por lo tanto, se logra escribir "sobre" administración, lo que supone que el desarrollo y la finalidad de los escritos instala la naturaleza moderna de este tipo de conocimiento. Este aspecto debe destacarse para no cometer la exageración de poner en el mismo plano de continuidad a las sociedades premodernas con la sociedad industrial de los siglos XIX y XX, como lo sugieren algunos autores que exponen el pensamiento administrativo (Chiavenato, 2006; Wren, 2008; George y Álvarez, 2005; Hernández y Rodríguez, 1994), quienes al buscar los supuestos "orígenes" de la administración se remontan a los grandes imperios del Oriente, a la antigüedad grecorromana y a la Edad Media, y dan por sentado que sus "prácticas de administración" se corresponden con lo que la sociedad moderna ha fundado como "administración", con lo cual cometen un craso anacronismo debido a que no reconocen las 
particularidades históricas de este campo de conocimiento propio del mundo moderno, tema éste que comprende el desarrollo de este artículo.

\section{Prácticas de organización del trabajo en las empresas capitalistas}

Las transformaciones culturales y tecno-económicas que tuvieron cabida en 0ccidente a partir del Renacimiento y la consiguiente "racionalización de la vida" que inició la modernidad, tuvieron por resultado que el orden profano de las cosas terrenales definiera el sentido de la vida humana, al destituir su antiguo sentido sacro y espiritualista con el tono humanista característico de la época (Von Martin, 1998). Parafraseando a un historiador, con esta importante transformación, la salud del cuerpo comenzó a ser más importante que la salvación del alma. De esta forma, la modelación del mundo material y social en función de los ideales de dominio, abundancia, confort material y "felicidad" fue un imperativo cada vez más urgente, lo que explica la centralidad que fue logrando el sistema económico en la vida social, impregnando todo con su racionalidad capitalista de productividad, cálculo y eficiencia (Groethuysen, 1985).

Con el advenimiento de la revolución tecno-científica de los siglos XVII al XIX, la sociedad de entonces se vio abocada a integrar cada vez más a la vida social $y$, a los procesos productivos en particular, elementos de la ciencia y de la tecnología moderna, con lo que la "racionalidad objetiva" trasmutó en "racionalidad instrumental" con sus ideales crematísticos e individualistas de los que es heredera la administración moderna (Marín, 2006, pp. 137-138).

A partir de 1780, en los inicios de la Revolución Industrial², la racionalización de los emergentes procesos productivos en las industrias estuvo acompañada de su vertiginosa expansión y diversificación, lo que hizo que quienes las administraban -casi siempre los mismos propietarios e inversionistas- se vieran en la necesidad de optimizar sus procesos productivos, pues, si bien, existían los medios económicos para que la industria subsistiera, la idea era que produjera los mejores resultados posibles y que continuara creciendo. Para el historiador William Ashworth (1978), el proceso de creciente mecanización, así como la necesidad de ejercer un estricto control de los asalariados reunidos de forma masiva en las fábricas, -donde se vieron obligados a trabajar uno al lado del

2 Eric Hobsbawm plantea que la Revolución Industrial tuvo fundamentalmente dos fases, la del algodón y las industrias textiles entre 1780 y los años de 1840 y, la de la industria pesada del acero, el hierro y el carbón, la llamada "era de los ferrocarriles", entre 1840 y 1895 (Hobsbawm, 1982, pp. 55-76, 105-128). 
otro, cuando antes lo hacían de manera separada y espontánea, y la necesidad de que cumplieran con los ritmos regulares de las máquinas, pues antes trabajaban de modo irregular y espontáneo-, obligó a pensar los problemas de administración y control de una forma inédita.

La aparición de la fábrica con su consiguiente concentración masiva de los obreros en un espacio y la división técnica del trabajo que ella supuso entre actividades productivas y de dirección fueron condiciones de posibilidad para que emergiera la administración como una práctica moderna de organización del trabajo productivo (Bendix, 1956); un "saber experto" que involucraba la ciencia y la técnica moderna, institucionalizado en el sistema científico y de educación formal. No obstante la poca nitidez que existe en los escritos de Carlos Marx al respecto, investigaciones posteriores indican que la emergencia de la fábrica con su característica división técnica del trabajo no se debió a un proceso de evolución que buscara una mayor eficiencia técnica, sino que la relación de jerarquía y control de tal escenario productivo era inherente a la dominación del trabajo por parte del capital (Uricoechea, 2002; Gaudemar, 1991; Coriat, 2000). En consecuencia, la función administrativa del proceso productivo que se hizo tangible como control del mismo supuso la imposición de la división técnica del trabajo fabril (y la especialización del trabajador), esquema al cual le subyace una rotunda separación entre el trabajo manual y el trabajo intelectual. Fue así como la fábrica, que se generalizó como sistema de producción hacia las décadas de 1830/1840 en Inglaterra, hizo indispensable para su desarrollo que se despojara al trabajador del control del proceso del trabajo, que en adelante se concentró en una estratificada capa de mandos medios de capataces y administrativos, representantes del empresario (Hobsbawm, 1982).

Según Ashworth (1978, p. 97), la historiografía sobre las primeras empresas del siglo XIX ha revelado que sólo en algunas de ellas se dedicaba especial atención y "una investigación muy cuidadosa a los problemas fundamentales de la gerencia", mientras que en la gran mayoría, los problemas de organización del trabajo y la producción se resolvían de forma empírica, "a medida que surgían, sobre la base de lo que pareciera conveniente y viable", sin consideraciones de largo plazo resultantes de la evaluación de alternativas. En este contexto, la expresión "sistema de fábricas" comprendía una amplia variedad de prácticas racionales de dirección y organización del trabajo fabril.

Para el caso de la Inglaterra del siglo XVIII, Edward Thompson y Paul Mantoux han mostrado el tortuoso y conflictivo proceso que supuso el sometimiento de los obreros (muchos de ellos mujeres y niños) a una rígida disciplina por parte de los directivos y capataces 
de las fábricas, mediante la imposición de los ritmos abstractos del reloj y la regularidad mecanizada (Thompson, 2000; Mantoux, 1962). De allí que los códigos de disciplina estuvieran dirigidos a regular las nuevas interacciones sociales y las exigencias técnicas y laborales a que estuvieron sometidos los asalariados bajo el control de una "dirección técnica unificada" (Wolf, 2006, p. 332). En su clásico trabajo sobre los sistemas punitivos de la Europa occidental, Michel Foucault plantea que tal régimen disciplinario supuso nuevas maneras de ejercicio del poder mediante el control y vigilancias jerárquicas requeridas por el novedoso aparato productivo, formas de domesticación de los obreros mediante un complejo conjunto de técnicas y dispositivos de poder dirigidos al correcto encauzamiento de sus conductas con la finalidad de regirlas y hacerlas completamente útiles (Foucault, 2009).

Los códigos de disciplina impuestos en las fábricas significaron la imposición de multas, sanciones, violencia física y la expulsión de los obreros debido a sus torpezas y tardanzas en el trabajo (Jorda, 1999). Durante el siglo XIX, con el tiempo tales códigos se hicieron menos violentos, pues la implementación de sistemas administrativos más modernos y sistemáticos permitieron un mejor acople de los trabajadores a los códigos de la vida fabril; así, aquellos asumieron de forma más efectiva las formas de vida regularizadas del trabajo fabril (Ashworth, 1978).

A finales del siglo XIX, en el contexto del capitalismo monopólico (más propio de los Estados Unidos de Norteamérica), y dado que las innovaciones técnicas estaban cada vez más extendidas entre los empresarios, en medio de una férrea competencia, la optimización de los procesos productivos debió lograrse con mejoras administrativas, de allí que fuera imperativo pensar la organización de los talleres y fábricas como problemas técnicos y científicos que no se podían resolver mediante soluciones empíricas y violentas; fue en este contexto que Frederick Taylor propuso su sistema de racionalización del trabajo de los obreros (Hopenhayn, 2002). No obstante, el proceso de cambio no fue nada lineal pues se siguieron aplicando medidas de coacción sobre los trabajadores, y el perfeccionamiento técnico como si fuera una solución a la organización del trabajo fabril.

\section{Emergencia de la administración como práctica discursiva. Primera etapa: 1780-1850}

Los problemas que tuvieron que enfrentar los primeros empresarios, ingenieros, técnicos y dirigentes de fábricas en cuanto a las funciones de planificación, controly organización del trabajo, fueron de gran estímulo para que produjeran los primeros escritos referidos 
al "sistema de fábricas". De manera que la creciente magnitud de los negocios, el mayor compromiso de la ciencia y la técnica con el mundo de la producción y la "cultura impresa" y "escolarizada" que ellas suponen, así como la necesidad de transformar los códigos de disciplina por métodos más sistemáticos y eficientes, mostró a los empresarios que había razones para escribir sobre su experiencia como directivos. Ello suponía guardar memoria escrita de su vida en la dirección de fábricas, e incluso la pretensión de investigar al respecto. A pesar de que fuera de la ingeniería "la dirección de empresas como profesión estaba todavía en su fase embrionaria", el ambiente fue propicio para la producción de los primeros textos sobre problemas técnicos y de administración de las empresas con los que se pretendía publicitar experiencias directivas de forma sistemática (Pollard, 1987).

Al indagar la génesis de la dirección de empresas modernas en Inglaterra, entre 1750 y 1830, el historiador Sidney Pollard identifica los primeros y "pocos casos aislados de reflexión consciente" sobre un asunto que hasta entonces había sido eminentemente práctico (1987, pp. 329-333). Un caso es el de la sociedad de Matthew Boulton y James Watt en la década de 1770, cuyos socios pretendieron resolver las crisis periódicas de su empresa de fabricación de máquinas por medio de la "regularidad, la delegación de poderes y la división de funciones". Boulton debió su éxito no solo a sus cualidades de negociante sino a su talento para lograr la regularidad de sus trabajadores en sus puestos de trabajo y con el proceso general de la fábrica, lo que puso en evidencia su talento para dirigir hombres (Mantoux, 1962).

Un segundo ejemplo es el del más reputado directivo de principios del siglo XIX, Robert Owen (1771-1858), manufacturero filántropo en Manchester y en New Lanark, cuyas innovaciones no consistieron en su capacidad de negociación ni de comercialización, sino por su metódica y eficiente disposición de las fábricas y de su cuidadosa selección y formación de subdirectores. Owen se destacó por lo que hoy se denomina "gestión del personal", a partir de un trato más considerado hacia los trabajadores, como parte de un mejor incentivo para su productividad (Santos, 2002; Mantoux, 1962).

Se pueden destacar las iniciativas de algunos empresarios de principios del siglo XIX, como el caso de Benjamin Gotts, cuyos apuntes revelan sus mejoras en la dirección de fábricas de tejidos, y el de William Brown, en el hilado de lino, cuyos "cuadernos de apuntes", de entre 1818 y 1823, muestran "una actitud esencialmente científica hacia los problemas de técnicos y administrativos" y que iba más allá de la práctica de muchos contemporáneos en cuanto a los problemas de organización, supervisión de mano de obra y al detallar por escrito las funciones de los subdirectores. Es notorio que Brown mostrara una actitud 
moderna para su época, al estimar la escritura como forma consciente de sus prácticas como directivo, y que la concibiera como mecanismo de cualificación de la administración misma, al decir: “sin duda todos los directores de fábricas grandes y bien dirigidas escriben mucho, ya que de otro modo no podrían jamás establecer el orden y la disciplina entre sus obreros, ni introducir mejoras y regularidad en la construcción y el montaje de su maquinaria" (citado por Pollard, 1987, p. 331). Algunos apuntes de Brown revelan una orientación de la escritura hacia mejoras localizadas de prácticas administrativas, pero no han sido reconocidas como una formalización del saber administrativo. Pollard sugiere que pudo existir una media docena de casos similares al de Brown, empresarios que "intentaron una sistematización deliberada de las experiencias en materia de dirección de empresa dentro de la industria", pero que sus ideas no tuvieron la resonancia debida, pues se trataba de "experiencias y profesionales aislados" (1987, pp. 331-332).

Otros testimonios para el caso de Francia revelan que, debido al sello personal que tenía el conocimiento de los capitanes de industria, los primeros escritos acerca de lo que se denomina la administración, tenían el carácter de legado patrimonial familiar. Louis Bergson expone el ethos del empresario moderno a partir de las vidas de empresarios como Jean Zuber y Antoine-Joseph Santerre en la Francia de finales del siglo XVIII. Su cultura de elite y la riqueza de su experiencia como capitanes de industria los motivó a escribir libros que se ubican entre la memoria autobiográfica -un legado de experiencias para ser retomadas por sus sucesores directivos de familia-, y el moderno libro de administración de empresa, que surgiría sólo a principios del siglo XX:

(...) ambos obedecieron a una misma preocupación por transmitir el patrimonio, constituido, más allá de sus fortunas y bienes, por su experiencia técnica y de gestión, mediante la forma de un texto escrito al final de su vida, dentro de una perspectiva (normal para ellos) de legado y continuidad del negocio industrial y familiar; en el caso de Santerre, muerto en 1809, se trata de L'Art du Brasseur (1807) dedicado a sus hijos, obra notablemente completa que trata todos los aspectos de la empresa (Bergson, 1995, p. 141).

El anterior caso parece ajustarse a lo señalado por Daniel Wren (2008, p. 86), en tanto que los primeros escritos sobre administración tuvieron un sentido localizado y personal, bajo el tono de "consejos", sabiduría y talento individual. Para ilustrar este fenómeno puede citarse el caso del escocés James Montgomery, quien escribió sobre administración hacia 1832 (Pollard, 1987); al decir de Wren, sus consejos eran técnicos y pretendían 
bajar los costos, "evitar rigores innecesarios a la hora de disciplinar a los subordinados" y se orientaron a la industria del algodón ${ }^{3}$.

En la industria del algodón también fue muy importante la obra de Adrew Ure (1778-1857), quien estudió en las universidades de Edimburgo y Glasgow y fue uno de los primeros en plantear la necesidad de formar administrativos y directivos. En su The philosophy of manufactures (Londres, 1835), consideró los problemas técnicos de fabricación en las industrias textiles y de administración como el acople entre máquinas y hombres y, como principio fundamental planteó la sustitución de las habilidades manuales por la mecanización. Ure entró en contacto con el barón e ingeniero francés Charles Dupin, quien también se destacó por sus escritos sobre administración, éste visitó las fábricas de Glasgow, entre 1816 y 1818, y dio testimonio de que algunos de sus dirigentes habían sido formados por Ure a partir de cursos de ciencias que impartió a trabajadores en la Universidad Anderson de Glasgow (Wren, 2008).

Para los ferrocarriles "un experto en dirección de minas daba en 1830 detallados consejos sobre cómo encontrar un director con plenos conocimientos científicos y mecánicos que pudiera también dirigir, organizar y desarrollar métodos de bajos costes" (Pollard, 1987). En este campo es bien conocida la obra de Charles Babbage (1791-1871), matemático británico, cuyo libro On the Economy of machinery and manufactures publicado en 1832, fue reeditado cuatro veces en el lapso de cuatro años. Visitó una amplia variedad de fábricas británicas y francesas y estudió las habilidades y gastos del trabajo obrero, para lo cual propuso “principios económicos de fabricación” (Wren, 2008; Merril, 2000). En cuanto al sector textil de Francia hay que citar al ya mencionado Dupin (1784-1873), quien se desempeñó como profesor de matemáticas y economía en el Conservatorio de Artes y Profesiones de París y cuyas obras reclamaron la atención de los primeros gimnastas atentos a estudiar la mecánica del cuerpo y el rendimiento energético de los alimentos de los obreros (Vigarello y Holt, 2005; Wren, 2008).

De igual forma es necesario traer a colación al no tan conocido Jean Gustave Courcelle-Seneuil (1813-1892), el prototipo de los teóricos del siglo XIX, versado en economía política, quien incursionó en el manejo de empresas y la dirigencia política. En 1854 publicó un "Manual de negocios", uno de los "ancestros más modernos" de la administración, dirigido a los jefes de empresa; obra "fundada en hechos y legitimada por la economía

3 Peter Druker cita un texto de 1791, al que califica como uno de los primeros escritos sobre administración, "Informe sobre las manufacturas", del norteamericano Alexander Hamilton (1757-1809) (1995, pp. 33-34). 
política" cuya preocupación por el mercado anunciaba problemas del marketing moderno y la administración de personal (Ribeill, 1994, pp. 28-43).

No obstante la importancia de esta serie de autores y de sus obras pioneras, la mayoría de ellas escritas y publicadas entre las décadas de 1820 y 1840, no equivalían a una doctrina ni al cuerpo teórico de una profesión; tampoco se trataba de "una tecnología y menos de una ciencia que pudiera ser enseñada en manuales" (Pollard, 1987, p. 332). Ello se correspondía con las condiciones sociológicas de los directivos, pues aunque se trataba de nuevos profesionales en ascenso desde 1760, todavía hacia las décadas de 1830/1840 estuvieron subordinados a los accionistas, propietarios de las empresas y empresarios fundadores, y no conformaron una clase social, sino que se trataba de "individuos aislados" (ibíd., p. 186). La inexistencia de un cuerpo teórico sistemático y generalizable en el campo de la administración para la época también se explica a partir del hecho que no se presentara una tajante separación entre los aspectos técnicos y los administrativos. Al respecto, la historia empresarial sobre las tempranas fases de la Revolución Industrial es reiterativa en señalar que lo característico del empresario de las manufacturas era que apenas sí merecía el nombre de industrial y la industria era para estos negociantes una forma de comercio. Fases posteriores del desarrollo capitalista harían que el comerciante ejerciera control sobre el proceso de producción y explotara el trabajo ajeno formalmente libre, sin abandonar el comercio, de modo que sintetizó en su sola persona las funciones de capitalista financiero, empresario y director de fábrica (Mantoux, 1962), con lo cual no tuvo un rol propiamente directivo.

La función directiva moderna implica ocuparse de una compleja serie de asuntos “internos" a la organización, pero en aquel contexto de novedoso desarrollo tecnológico y de profundas transformaciones sociales, los asuntos "externos" demandaban la atención de los directores, como las que hoy corresponden al Estado o a las comunidades, entre ellas "la construcción de caminos, canales, puertos y aldeas enteras, iglesias, escuelas, bancos y tiendas" (Pollard, 1987, p. 333). Al respecto, la cultura de las élites empresariales estaba imbuida de las tradiciones de paternalismo y autoridad para orientar las "relaciones industriales" con lo cual quedaban absorbidos por acciones sociales que trascendían la empresa misma (Cassis, 2001, pp. 80-82; Barley y Kunda, 1992, pp. 82-84). 0tro factor a tener en cuenta es que la formación empírica de los directivos se orientaba a los aspectos específicos de la producción de las empresas lo que no facilitaba el intercambio de experiencias y personal entre ellas: no existía "ningún código común de conducta administrativa, ni un conjunto universal de expectativas" sobre cómo debía actuar un directivo (Wren, 2008; Mantoux, 1962). 
A los determinantes anteriores hay que sumar que definitivamente el contexto estuvo marcado por las urgencias de la inventiva, la innovación y la tecnología, de modo que fomentó toda una ideología basada en el progreso por obra de la tecnificación misma (Bendix, 1956); una visión mecanicista que lo impregnaba todo y, en particular, la concepción de los trabajadores, lo que impidió ver su carácter "humano", es decir su condición psicológica en función de la producción como un complejo fenómeno social (ibíd.). En tal contexto se identifica la primera generación de capataces, artesanos, técnicos e inventores (antes que ingenieros), empresarios directivos que encarnaban el "empirismo práctico del pueblo inglés" (Mantoux, 1962, pp. 98, 201-202). Sólo cuando las formas de organización del trabajo hicieron énfasis en la productividad del trabajo humano y no en la de las máquinas, se desarrollaron sistemas directivos que abordaron de manera global las interacciones de los trabajadores con el todo complejo de la fábrica, de forma que el conflicto de clase entre capital y trabajo se abordó de una manera diferente (Hobsbawm, 1982, pp. 71, 89).

Otro aspecto que a principios del siglo XIX impidió la emergencia de una moderna doctrina administrativa que pudiera socializarse como un saber disciplinar ${ }^{4}$, es el hecho que la experiencia directiva de los capitanes de industria revelaba talentos de corte fundamentalmente personal, y de allí que fueran asumidos como un "arte" sin posibilidades de socializarse mediante la educación. En palabras de Wren se trataba de "un arte personal, no una disciplina; pragmático, no teórico; y localista, no universal" (2008, p. 90). Así las cosas, las dotes administrativas estaban subsumidas en las funciones y roles de las figuras que sociológicamente dominaron la centuria "los genios técnicos, el inventor-pionero y el fundador propietario" (Wren, 2008, p. 114).

Por último, debe considerarse "el estado de la diseminación del conocimiento", esto es, que la "cultura escolarizada" asociada con la proliferación de los libros y el ejercicio de la escritura no habían logrado afincarse como rutina de vida diaria y profesional. En consecuencia, fue sólo hasta finales del siglo XIX que las exigencias industriales y del mercado forzaron a las empresas a extenderse de forma horizontal y luego vertical, con lo cual requirieron de nuevas formas de organización y supervisión, de forma que según Alfred Chandler la "mano visible" tomó forma con "la figura del dirigente y del ejecutivo asalariado", lo que estimuló el auge del “capitalismo gerencial” (2008, pp. 17-29).

4 En palabras de Foucault, "se llama disciplinas a unos conjuntos de enunciados que copian su organización de unos modelos científicos que tienden a la coherencia y a la demostratividad, que son admitidos, institucionalizados, trasmitidos y a veces enseñados como unas ciencias" (2002, p. 299). 
Hacia los años de 1880 la creciente magnitud de la empresa norteamericana, al igual que su compleja estructura jerárquica de directivos, constituyeron la institución y el grupo social más influyentes del momento, dando forma a lo que Chandler ha denominado el "capitalismo gerencial" (2008, pp. 17-29). Ello fue el resultado de diversos procesos entre los que vale destacar el crecimiento y diversificación de las empresas, la profesionalización de sus directivos y la separación entre las funciones de control (administración) y propiedad. La centralidad de los administradores fue más nítida en los años posteriores a la Primera Guerra Mundial (1914-1918), de modo que de allí derivan los perfiles profesionales que han caracterizado hasta nuestros días a los altos directivos y gerentes de organizaciones. Desde entonces, los directivos de las grandes empresas industriales "crearon y perfeccionaron un nuevo tipo de estructura global" que permitió "que los mandos medios se dedicaran a la gestión y coordinación de los procesos de producción y distribución, y que los altos directivos se ocuparan de evaluar, planificar y asignar los recursos para la empresa en su conjunto. Al mismo tiempo, el criterio y la formación de estos directivos industriales era cada vez más profesional. Estos dos hechos intensificaron aún más el poder económico de las grandes empresas industriales y de los hombres que las dirigían" (Chandler, 2008, p. 634).

\section{Emergencia de la administración como práctica discursiva. Segunda etapa: La escritura sistemática, 1850-1930}

Después de 1850 y hasta las décadas de 1920/1930, particularmente en los Estados Unidos de Norteamérica, se presentaron propuestas más concretas y de mayor difusión escrita que apuntaban a la organización metódica y planeada del trabajo en fábricas y empresas, a partir de observaciones sistemáticas que llegaron a convertirse en textos escritos con pretensiones de cientificidad, y que constituyen el cuerpo de conocimientos que fueron configurando un campo discursivo denominado "Administración científica". En este panorama, es importante reconocer una pléyade de autores, citados en la literatura clásica sobre el pensamiento administrativo como antecesores y contemporáneos de las figuras fundacionales de la administración moderna; en Estados Unidos, Frederick Taylor (1865-1915) con sus Principios de la administración científica (1911), y en Francia, Henry Fayol (1841-1925) con su Administración industrial y general (1916).

Las diversas iniciativas de producción escrita sobre los problemas de los talleres y fábricas fueron dando forma a un saber más sistemático y racionalizado y sus autores, en los países de mayor desarrollo industrial como Inglaterra, Francia y los Estados Unidos, fueron militares, matemáticos, filósofos, economistas y, principalmente, ingenieros. 
Apartes de sus libros, artículos, conferencias e informes para sociedades científicas y gremiales o para empresas, debido a su rol como consultores, han sido compilados por Harwood Merril (2000). Algunos de sus nombres se pueden citar como sigue: Charles Babbage (1791-1871), el Capitán Henry Metcalfe (1847-1917), Henry Robinson Towne (1844-1924), Henry Lawrence Gantt (1861-1919), Harrington Emerson (1853-1931), Frank Bunker Gilbreth (1868-1924) y su esposa Lillian Moller Gilbreth, Oliver Sheldon (1849-1933), Mary Parker Follet (1868-1933) y Jean Gustave Courcelle-Seneuil (18131892) (Wren, 2008; Ribeill, 1994), entre otros. Muchos de estos autores escribieron los primeros textos que para la época podían ser calificados de académicos y "científicos", de acuerdo con los nacientes formatos del "artículo experimental" en boga, que nació de los intercambios epistolares de los filósofos de la naturaleza desde mediados del siglo XVII (Bazerman, 2008).

Si se hace un inventario de los textos citados y compilados por Merril para cada uno de estos autores, se aprecia que la amplitud de problemas acerca de la administración de talleres y fábricas cubre temas tan diversos como: la medición de tiempos y movimientos, la división técnica del trabajo como forma de minimizar costos de producción, las innovaciones técnicas adaptadas a la organización, el estudio de las destrezas de los obreros, sus motivaciones para el trabajo, el manejo de las herramientas con miras a lograr su mayor eficiencia, la innovación técnica como optimización de la mano de obra, la capacitación como medio de regulación del trabajo obrero, sus condiciones de vida dentro y fuera de las fábricas, pautas de dirección y autoridad con el personal y su reclutamiento, entre otros temas (Merril, 2000).

Estos y otros escritores que permanecen anónimos o en un lugar secundario participaron de la administración moderna, a partir de sus intentos por sistematizar y organizar los tradicionales conocimientos prácticos de la administración y darles forma teórica, pretendiendo recoger y presentar de forma sintética, metódica y comprensible sus propias experiencias como base de una doctrina con pretensiones de ser difundida en los medios académicos y empresariales. Muchos de ellos plantearon como "principios", lo que en realidad fueron preceptos, normas o consejos (Kliksberg, 1978).

A veces, sin ser conscientes de ello, la labor de estos primeros teóricos se centró en “pensar las prácticas" que tradicionalmente habían asumido en las empresas para organizar el trabajo, muchas de ellas derivadas de la experiencia de toda una vida como empresarios, técnicos, directivos o consultores. La transformación discursiva que implicaba disponer todo un saber tradicionalmente empírico, con una gran carga de oralidad y subjetividad, 
derivada principalmente de experiencias personales circunscritas a empresas o de amagos de investigación, implicaba un exigente trabajo de reconstrucción escrita basado en la “sistematización" del conocimiento y su reinvención teórica. Ello implicó un proceso mental en que una acción pasa del conocimiento empírico al universo de las ideas estructuradas y abstractas para iluminar de nuevo la acción. Se trataba de "organizar textualmente las experiencias", elaborarlas teóricamente, con miras a la producción de saber sobre ellas mismas, con el objeto fundamental de hacerlas más efectivas y comunicables. Al modo de las ciencias naturales y de la física clásica (con la cual muchos autores estaban familiarizados por su formación académica), los primeros directores de fábrica pretendieron recoger por escrito su saber empírico practicado en las empresas con objeto de establecer "principios" universales dirigidos a la organización del trabajo, que pudieran aplicarse independientemente de sus especificidades. Fue así como a finales del siglo XIX hizo su emergencia histórica "la administración como realidad codificada y como realidad social" (Chanlat, 2006, pp. 30-31).

A partir de estas propuestas escritas, las "prácticas administrativas" fueron conquistando su propio discurso doctrinal y se convirtieron en un saber teórico que en palabras de Foucault puede ser denominado "prácticas discursivas", es decir, prácticas que lograron trascender la acción empírica e inmediata y constituirse en un saber formalizado en textos escritos. Con Michel Foucault, entiendo las "prácticas discursivas" como "un conjunto de reglas anónimas, históricas, siempre determinadas en el tiempo y el espacio que han definido en una época dada, y para un área social, económica, geográfica o lingüística dada, las condiciones de ejercicio de la función enunciativa" (Foucault, 2002, pp. 198; 2005, pp. 14-38). Las prácticas discursivas delimitan todo un conjunto de enunciados que (en un campo disciplinar) definen todo aquello que puede decirse, expresarse e imaginarse. Se trata de un sistema de relaciones enunciativas cuyas propias reglas de juego definen de qué se puede hablar (los procesos de racionalización en la organización productiva), quién puede hablar (empresarios, directivos, consultores, académicos), desde qué puntos de vista (la propiedad y el control de la organización), con qué autoridad y calificaciones (derivadas de la experiencia o la formación académica), y la delimitación y agrupación de problemas y objetos con una unidad propia (el ámbito organizacional).

Los discursos, como práctica social, no son un reflejo de la realidad, sino que son constitutivos de ella, lo que significa que poseen vida propia y determinan la producción discursiva de la realidad con las representaciones que de ella agencian (Jäger, 2003). Hablar de prácticas discursivas implica hablar de "prácticas productoras de saber", de un saber entendido como un "agenciamiento práctico", es decir, un dispositivo de enunciados 
(formaciones discursivas) y de fenómenos visibles (formaciones no discursivas). Hablar de la administración como una práctica discursiva conlleva un primado de la palabra sobre los procedimientos (las "artes de hacer" o los hechos sin consciencia), en la medida en que estos se dejan determinar-describir y enunciar- parcialmente por la primera, pero la primacía no implica su reducción (Veiga-Neto, 1997).

No obstante que los planteamientos de Taylor aspiraban a ser "científicos", el más alto estatuto del conocimiento en una era de imperante positivismo, su doctrina estaba lejos de serlo. Su método inductivo, manifiesto en inferencias y generalizaciones con base en experimentos no controlados y en su experiencia personal, lo llevaron a plantear principios para la racionalización del trabajo de los obreros en los talleres. Sin embargo, su sistema administrativo fue más una "filosofía" que, como indica Carlos Dávila, no es deducible "de una teoría, de la cual a un nivel más concreto se desprendan hipótesis, y a otro más concreto aún, recomendaciones para la acción, sino por el contrario, son unas prescripciones de acción, inferidas de instancias, (ejemplos) en que fueron utilizadas. Sin embargo, su método fue más sistemático que el de Fayol" (2001, pp. 102-103).

Registrar por escrito experiencias personales por parte de los directivos y capitanes de industria tiene que ver con la pretensión racionalizadora del siglo XIX de una mayor precisión y exactitud en el cuerpo de los conocimientos profesionales. En este contexto de empirismo imperante y de la física clásica que se imponía como modelo de cientificidad, la formación textual de un saber que tradicionalmente había sido oral o precariamente escrito, contribuyó a originar criterios de orden, racionalidad, exposición fáctica, medios de verificación y argumentación propios de las ciencias, con la finalidad de crear un corpus teórico susceptible de ser difundido ampliamente en la sociedad, más allá de los círculos especializados del saber (Podestá y Jurado, 2003). Así, los primeros autores de escritos de administración de empresas, que posteriormente serían reconocidos como los fundadores del movimiento de la administración moderna -Taylor y Fayol-implicaron una alteración discursiva en las prácticas administrativas a partir de su configuración escrita, con lo cual, la administración ingresaba al campo de la investigación moderna con su presentación racional y uso pedagógico y didáctico (Morrison, 1995).

La "Organización textual de la experiencia" que suponen las obras de tales autores se refiere a los modernos conceptos románticos de "obra", "autor", "originalidad" y "espíritu creador" que permiten considerar una obra como cerrada en sí misma, como apartada de otras y como una unidad en sí misma (0ng, 2009, p. 132). Los medios de expresión escrita están relacionados con las instancias sociales que hacia el siglo XIX conferían 
validez y reconocimiento por medio de revistas especializadas, libros, comunidades científicas y académicas y la transformación de sentido que el nuevo soporte escrito implicó (Chartier, 2000).

No obstante la diversidad de interpretaciones sobre la importancia atribuida a Taylor, la mayoría de los autores adjudican a éste un papel fundamental en la transformación discursiva de la administración, lo cual supone su capacidad para sistematizar y formular con mayor coherencia teórica los planteamiento básicos de un saber que se configuraba como un campo teórico relativamente autónomo respecto de la economía ${ }^{5}$ y de la ingeniería. Esta última considerada "ciencia aplicada a la industria" apoyada en cálculos matemáticos y en la física para fundar decisiones e innovaciones de orden técnico (Gouzevitch y Vérin, 2005, pp. 118-120). Así, las cosas, para 0mar Aktouf “Taylor no inventó nada que fuese totalmente nuevo, pero efectuó la síntesis de las ideas que germinarían y serían reforzadas en Gran Bretaña y los Estados Unidos durante el siglo XIX y las presentó en un todo coherente y razonado. A una serie de iniciativas y experimentos disparatados les dio una filosofía y un título" (2001, p. 47). Al igual que Taylor, con su texto y sus planteamientos, Fayol inauguró una ruptura histórica de considerables consecuencias, entre la administración como saber empírico, que para la época se adquiría exclusivamente en el mundo de los negocios, y la administración como corpus teórico que iniciaba así su visibilidad y legitimidad desde las instituciones de educación superior, ámbitos donde se centralizan las prácticas de enseñanza de la sociedad moderna. Fayol representa no sólo una ruptura más explícita entre la administración y la ingeniería (lo "técnico"), sino entre la formación empírica y la académica, es decir, entre el mundo de los negocios y el sistema de educación formal (Popescu, 1956).

La formación profesional en administración tuvo por materia prima la "doctrina" propuesta por hombres de empresa como Fayol, quien era consciente que aquella cobraba existencia propia mediante su construcción escrita, pues de lo contrario, se trataba de una memoria personal, frágil y efímera, cuya existencia no trascendía la vida de su portador: "la mayor parte de los grandes jefes no tienen el tiempo ni el gusto de escribir y desaparecen sin dejar frecuentemente ni doctrina ni discípulos" (Fayol, 1994, pp. 21-

5 A diferencia de los teóricos de la administración, centrados en las "manufacturas", los economistas se ocuparon de los problemas de la producción y la eficacia. "La economía política clásica fue la primera ciencia social en preocuparse por la producción y la eficacia. Los primeros economistas (...) desarrollaron una ciencia de las riquezas que ponía el acento en el intercambio, el trabajo y la división que resultaba de ello. De manera general, quienes hasta entonces se habían interesado más de cerca por el mundo de la producción (...) se preocupaban sobre todo por sus aspectos técnicos" (Chanlat, 2006, p. 35). 
22). No obstante que su libro no se basaba en investigaciones sistemáticas, la obra de Fayol manifiesta un espacio inédito hasta entonces, de significativa trascendencia para la formalización e institucionalización de la educación en administración, pues con ello, la educación formal y no la experiencia empírica o la capacidad técnica de los ingenieros, se convirtió en criterio para la calificación profesional de los directivos de empresas; una forma de sancionar el largo proceso histórico que supuso la formación del Capitalismo, de transferencia de las funciones de conocimiento y control del trabajo por parte de los trabajadores a los administradores, y de separación de estos con respecto de los empresarios (Schweitzer, 2001). Para entonces fue claro el ascenso y configuración de una nueva élite de directivos especializados en el control y coordinación de los procesos empresariales (Chandler, 2008). Una lectura ingenua de tal fenómeno vería natural la extensión de la educación en las clases altas de Europa, si no fuera porque ello expresa la consolidación del Capitalismo y, por lo tanto, la relación social de dominación de la nueva clase burguesa integrada por la elite de directivos con relación a las capas de subordinados de la clase obrera (Uricoechea, 2002; Foucault, 2005).

Michel De Certeau destaca el papel fundamental de la escritura en la configuración de los objetos de conocimiento modernos, al señalar que se trata de una "razón productora" que fabrica un objeto de conocimiento; "la escritura es una metáfora del capitalismo" desde su disposición productora de saber, pues en la página se opera una “inversión industrial” en la que algo es recibido, transformado y producido ${ }^{6}$. De allí que exprese el nuevo poder burgués para "hacer la historia al fabricar lenguajes" (2007, pp. 148-152).

Todo lo anterior manifiesta que las diversas iniciativas de los directivos de industria por trascender las prácticas administrativas llevó a objetivarlas, como resultado de la separación operada entre sujetos y sus prácticas, entre quien conoce y lo conocido, entre sujeto y objeto de conocimiento (0ng, 2009). En este sentido, la construcción de la administración como práctica discursiva con sus experiencias fundadoras: la racionalización del trabajo del obrero en la industria (Taylor) y la racionalización de la organización en su conjunto (Fayol), expresan que la objetivación de tales prácticas implicó un doble movimiento de fecundidad mutua: por un lado, la consolidación del poder del Capital

6 Roland Barthes señala que hacia 1850 (en plena Revolución Industrial) la literatura inició toda una valoración de la escritura no en función de su finalidad, sino por el trabajo que cuesta. Se elaboró la imaginería del escritor-artesano que como obrero en el taller pasa horas de esfuerzo y trabajo haciendo su obra. La metáfora del obrero/taller hace que el valor-trabajo remplace al valor-genialidad (2006). 
sobre los obreros, representado en la dirección de fábricas, y por el otro, como lo han mostrado algunos autores, el establecimiento de nuevos dispositivos de saber, derivados de la administración como profesión, fundada en la sistematización de sus prácticas. Acá radica la complejidad del trabajo sistemático y sistematizador de Taylor y Fayol, al intentar "escribir las prácticas" resultantes de ancestrales necesidades y experiencias colectivas con la finalidad de construir sistemas productivos eficientes y de producir y difundir tales conocimientos teóricos en textos que, con el tiempo, fueron identificados como los textos clásicos de la administración.

\section{Consideraciones finales}

Los escritos de Fayol y Taylor en el escenario histórico de principios del siglo XX, son parte de una tradición escrita a lo largo de la Revolución Industrial, y significaron un distanciamiento de lo que "la administración" había sido durante siglos, una práctica social y cultural sin discurso teórico ni doctrina, orientada empíricamente al control y organización de los recursos económicos, cuyo ejercicio acontecía en diversos escenarios de la vida social, mientras que en las sociedades modernas ello acontece fundamentalmente en organizaciones productivas. En este sentido, no se ha valorado suficientemente la transformación histórica y la ruptura epistemológica que supuso el paso de la administración como "práctica", a secas, a una "práctica discursiva". Ello se debe a que algunos de los más reconocidos autores que recopilan el pensamiento administrativo no definen con todas sus consecuencias la ruptura que se operó en el paso de una tradición empírica, de base fundamentalmente oral, a una escrita y formal, con fines de sistematicidad y racionalidad en el contexto de las ciencia moderna y del capital industrial.

Reconocer la importancia de la invención de una tradición escrita en administración implica una ponderación más juiciosa de lo que significa la escritura en su transformación epistemológica. La configuración escrita de la administración resultante de la sistematización de sus ancestrales prácticas se compadece con la formalización de la enseñanza y formación académica de los directivos de industria, la adopción de lenguajes, métodos y técnicas compartidas entre profesionales con funciones homogéneas, la internalización por sus practicantes del ethos propio de la profesión, de los criterios de publicación y evaluación del trabajo científico y del estilo académico y racionalista que les es típico (Núñez, 2010). Todo ello expresa una novedosa organización académica y “disciplinar del conocimiento" administrativo que antes estaba imbuido en la ingeniería y la economía política y cuya especialización permitió su escolarización como campo autónomo 
de saber ${ }^{7}$. Ello fue posible mediante un largo proceso de alfabetización y de expansión de la cultura escrita en la sociedad occidental, y entre los directivos de empresa en particular, con su consiguiente organización social mediante instituciones disciplinarias como la escuela, el cuartel y la fábrica. Este complejo proceso histórico se explica dentro del nuevo orden europeo instaurado durante la Revolución Industrial, a partir de inéditas exigencias de organización social y política, pero sobre todo económicas, como el colonialismo, el capitalismo y por supuesto la industrialización, a los cuales debe la administración, su emergencia histórica mediante su escritura.

\section{Referencias}

Abbagnano, N. (2001). Diccionario de filosofía. México D.F.: Fondo de Cultura Económica.

Aktouf, 0. (2001). La Administración: entre tradición y renovación. Cali: Editorial Universidad del Valle.

Ashworth, W. (1978). Breve historia de la economía internacional. Desde 1850. Madrid: Fondo de Cultura Económica.

Barley, R. y Kunda, G. (1992). Plan y dedicación: oleadas e ideologías de control normativo y racional en el discurso administrativo. Revista Tecnología Administrativa, 20, 80-107.

Barthes, R. (2006). El grado cero de la escritura, México D.F.: Siglo XXI Editores.

Bazerman, Ch. (2008), La escritura de la organización social y la situación alfabetizada de la cognición: extendiendo las implicaciones sociales de la escritura de Jack Goody. Revista Signos, 41 (68), 355-380. Recuperado el 12 de julio de 2010, de http://www.scielo.cl/ pdf/signos/v41n68/art01.pdf

Bendix, R. (1956). Trabajo y autoridad en la industria. Buenos Aires: EUDEBA.

Bergson, L. (1995). El hombre de negocios. En: M. Vovelle et al. (eds). El hombre de la Ilustración (pp. 129-150). Madrid: Alianza Editorial.

Cassis, Y. (2001). El empresario. En: H. G. Ute Frevert et al. (eds.). El hombre del siglo XIX (pp. 61-89). Madrid: Alianza Editorial.

Coriat, B. (2000). El tallery el cronómetro. Ensayo sobre el taylorismo, el fordismo y la producción en masa. México: Siglo XXI Editores.

Chandler, A. (2008). La mano visible. Barcelona: Editorial Belloch.

7 El proceso de la configuración "disciplinar" de la administración con la extensión e institucionalización de su enseñanza en los niveles de la educación superior en Europa y los Estados Unidos, la formación de asociaciones con sus propios códigos de ética y sus publicaciones y el desarrollo de la industria editorial de los textos fundacionales a partir de las décadas de 1910/20, requiere un mayor desarrollo que sobrepasa los alcances de este artículo, centrado fundamentalmente en lo que se ha denominado la "etapa arqueológica" (1780-1900). 
Chanlat, J. (2006). Ciencias sociales y administración. Medellín: Fondo Editorial Universidad EAFIT. Charbonnier, G. (2006). Entrevistas con Claude Lévi-Strauss. Buenos Aires: Amorrortu Editores. Chartier, R. (2000). Las revoluciones de la cultura escrita. Diálogo e intervenciones. Barcelona: Gedisa.

Chiavenato, I. (2006). Introducción a la teoría general de la administración. México: Mc GrawHill. Dávila, C. (2001). Teorías organizacionales y administración. Enfoque crítico. Bogotá: Mc GrawHill. De Certeau, M. (2007). La invención de lo cotidiano. 1. Artes de hacer. México: Universidad Iberoamericana, Instituto Tecnológico y de Estudios Superiores de 0ccidente.

Díaz, S. (2010). Taylorismo: saberes expertos y tecnología en Colombia. Aclaraciones conceptuales y esbozo de la historia del Taylorismo en Colombia 1950-1980. Recuperado el 15 de julio de 2010, de http://www.humanas.unal.edu.co/eristica/Taylorismo.pdf

Druker, P. (1995). La sociedad post capitalista. Bogotá: Editorial Norma.

Fayol, H. (1994). Administración industrial y general. Buenos Aires: El Ateneo.

Foucault, M. (2002). La arqueología del saber. Argentina: Siglo XXI Editores.

Foucault, M. (2005). El orden del discurso. Barcelona: Tusquets Editores.

Foucault, M. (2009). Vigilar y castigar. Nacimiento de la prisión. México: Siglo XXI Editores.

García-Pelayo, M. (1981). Los mitos políticos. Madrid: Alianza Editorial.

Gaudemar, J. (1991). Preliminares para una genealogía de las formas de disciplina en el proceso capitalista del trabajo. En: M. Foucault et al. Espacios de poder (pp. 85-121). Madrid: Ediciones de La Piqueta.

Gellner, E. (2003). Naciones y nacionalismo. Madrid: Alianza Editorial.

George, C. y Álvarez, L. (2005). Historia del pensamiento administrativo. México: Paerson Educación. González, P. (2005). Las nuevas ciencias y las humanidades. De la academia a la política. Barcelona: Anthropos Editorial.

Goody, J. (1990). La lógica de la escritura y la organización de la sociedad. Madrid: Alianza Editorial. Gouzevitch, I. y Vérin, H. (2005). Sobre la institución y el desarrollo de la ingeniería: una perspectiva europea. En: M. Silva (ed.). Técnica e ingeniería en España. El siglo de las luces. De la ingeniería a la nueva navegación (pp. 115-163). Tomo III. Zaragoza: Diputación de Zaragoza.

Groethuysen, B. (1985). La formación de la conciencia burguesa en Francia durante el siglo XVIII. México: Fondo de Cultura Económica.

Hernández y Rodríguez S. (1994). Introducción a la Administración: un enfoque teórico práctico. México D.F.: McGraw-Hill.

Hobsbawm, E. (1982). Industria e Imperio. Barcelona: Editorial Ariel.

Hopenhayn, M. (2002). Repensar el trabajo. Historia, profusión y perspectivas de un concepto. Buenos Aires: Grupo Editorial Norma. 
Jäger, S. (2003). Discurso y conocimiento: aspectos teóricos y metodológicos de la crítica del discurso y del análisis de dispositivos. En: R. Wodak y M. Meyer. Métodos de análisis crítico del discurso (pp. 61-100). Barcelona: Gedisa.

Jorda, H. (1999). Économie et innovation. París: L'Harmattan. Traducción de Isabel Cristina Chaparro.

Kliksberg, B. (1978). El pensamiento organizativo: del tayulorismo a la teoría de la organización. La "Administración Científica" en discusión. Buenos Aires: Paidós.

Mantoux, P. (1962). La revolución industrial en el siglo XVIII. Madrid: Aguilar.

Marín, D. (2006). El sujeto humano en la Administración: Una mirada crítica. Cuadernos de Administración, 19 (32), 135-156.

Merril, H. (comp.). (2000). Clásicos en Administración. México: Editorial Limusa.

Morrison, K. (1995). Fijación del texto: la institucionalización del conocimiento en formas históricas y filosóficas de la argumentación. En: J. Bottéro et al. (eds.). Cultura, pensamiento, escritura (pp. 133-187). Barcelona: Gedisa.

Nagel, E. (1994). La estructura de la ciencia. Barcelona: Paidós.

Núñez, J. (2010). La ciencia y la tecnología como procesos sociales. Lo que la educación científica no debe olvidar. Recuperado el 19 de julio de 2010 de http://www.oei.es/salactsi/ nunez00.htm

Ong, W. (2009). Oralidad y escritura: tecnologías de la palabra. México D.F.: Fondo de Cultura Económica.

Podestá, M. y Jurado, J. (2003). Fundamentos del saber Administrativo. Cuadernos de Difusión, 8 (15), pp. 81-100.

Pollard, S. (1987). La génesis de la dirección de empresa moderna. Estudio sobre la revolución industrial en Gran Bretaña. Madrid: MTSS.

Popescu, 0. (1956). Estudio preliminar. La racionalización del gobierno de la empresa. FayolFayolismo. En: H. Fayol. Administración industrial y general (pp. VII-XXXIX). Buenos Aires: El Ateneo Editorial.

Ribeill, G. (1994). Courcelle-Seneuil, fundador de la administración moderna de las empresas en la mitad del siglo XIX. En: J. Ph. Bouilloud y B. P. Lecuyer (dirs.). La invención de la administración. Historia y prácticas (pp. 28-43). París: L’Harmattan. Traducción de Rodrigo Zapata Cano. Medellín, febrero de 2014.

Ricoeur, P. (2011). Teoría de la interpretación. Discurso y excedente de sentido. México: Siglo XXI Editores y Universidad Iberoamericana.

Santos, M. (2002). Robert Owen, pionero del management. Sociología del Trabajo. 45, 97-124.

Shweitzer, S. (2001). El ingeniero. En: H. G. Ute Frevert et al. (eds.). El hombre del siglo XIX (pp. 91-110). Madrid: Alianza Editorial.

Taylor, F. (1994). Principios de la administración científica. Buenos Aires: El Ateneo. 
Thompson, E. (2000). Costumbres en común. Barcelona: Editorial Crítica.

Uricoechea, F. (2002). División del trabajo y organización social: una perspectiva sociológica.

Bogotá: Grupo Editorial Norma y Universidad Nacional de Colombia.

Veiga-Neto, A. (1997). Crítica pos-estructuralista y educación. Barcelona: Editorial Laertes.

Vigarello, G. y Holt, R. (2005). El cuerpo cultivado: gimnastas y deportistas en el siglo XIX. En:

A. Corbin, J-J., Courtine y G. Vigarello (dirs). Historia del Cuerpo. Tomo II. De la Revolución francesa a la gran guerra (pp. 295-354). Madrid: Taurus.

Von Martin, A. (1998). Sociología del renacimiento. México D.F.: Fondo de Cultura Económica.

Weber, M. (2006). La reforma protestante y el espíritu del Capitalismo. México D.F.: Fondo de Cultura Económica.

Wolf, E. (2006). Europa y la gente sin historia. México D.F.: Fondo de Cultura Económica.

Wren, D. (2008). Historia de la gestión. Barcelona: Belloch. 